\title{
Sodium para-aminosalicylic acid inhibits manganese-induced NLRP3 inflammasome- dependent pyroptosis by inhibiting NF-KB pathway activation and oxidative stress
}

Dongjie Peng ${ }^{1,2+}$, Junyan $\mathrm{Li}^{1,2+}$, Yue Deng ${ }^{1,2+}$, Xiaojuan Zhu ${ }^{1,2}$, Lin Zhao ${ }^{1,2}$, Yuwen Zhang ${ }^{1,2}$, Zhaocong Li ${ }^{1,2}$, Shiyan $\mathrm{Ou}^{1,2}$, Shaojun $\mathrm{Li}^{1,2^{*}}$ and Yueming Jiang ${ }^{1,2^{*}}$

\begin{abstract}
Background: The activation of NOD-like receptor protein 3 (NLRP3) inflammasome-dependent pyroptosis has been shown to play a vital role in the pathology of manganese (Mn)-induced neurotoxicity. Sodium para-aminosalicylic acid (PAS-Na) has a positive effect on the treatment of manganism. However, the mechanism is still unclear. We hypothesized that PAS-Na might act through NLRP3.

Methods: The microglial cell line BV2 and male Sprague-Dawley rats were used to investigate the impacts of PAS$\mathrm{Na}$ on Mn-induced NLRP3 inflammasome-dependent pyroptosis. The related protein of the NF-KB pathway and NLRP3-inflammasome-dependent pyroptosis was detected by western blot. The reactive oxygen species and mitochondrial membrane potential were detected by immunofluorescence staining and flow cytometry. The activation of microglia and the gasdermin D (GSDMD) were detected by immunofluorescence staining.

Results: Our results showed that Mn treatment induced oxidative stress and activated the NF-KB pathway by increasing the phosphorylation of p65 and IkB-a in BV2 cells and in the basal ganglia of rats. PAS-Na could alleviate Mn-induced oxidative stress damage by inhibiting ROS generation, increasing mitochondrial membrane potential and ATP levels, thereby reducing the phosphorylation of p65 and IkB-a. Besides, Mn treatment could activate the NLRP3 pathway and promote the secretion of IL-18 and IL-1 $\beta$, mediating pyroptosis in BV2 cells and in the basal ganglia and hippocampus of rats. But an inhibitor of NF-kb (JSH-23) treatment could significantly reduce LDH release, the expression of NLRP3 and Cleaved CASP1 protein and IL-1 13 and IL-18 mRNA level in BV2 cells. Interestingly, the effect of PAS-Na treatment in Mn-treated BV2 cells is similar to those of JSH-23. Besides, immunofluorescence results showed that PAS-Na reduced the increase number of activated microglia, which stained positively for GSDMD.
\end{abstract}

Conclusion: PAS-Na antagonized Mn-induced NLRP3 inflammasome dependent pyroptosis through inhibiting NF$\mathrm{KB}$ pathway activation and oxidative stress.

Keywords: Mn, PAS-Na, Oxidative stress, NLRP3 inflammasome, pyroptosis, NF-KB pathway

*Correspondence: lishaojun0613@163.com; ymjianggxmu@163.com

${ }^{\dagger}$ Dongjie Peng, Junyan Li, and Yue Deng have contributed equally to this article.

'Department of Toxicology, School of Public Health, Guangxi Medical University, Shuang-yong Road No.22, Nanning 530021, Guangxi, China Full list of author information is available at the end of the article

(c) The Author(s). 2020 Open Access This article is licensed under a Creative Commons Attribution 4.0 International License, which permits use, sharing, adaptation, distribution and reproduction in any medium or format, as long as you give appropriate credit to the original author(s) and the source, provide a link to the Creative Commons licence, and indicate if changes were made. The images or other third party material in this article are included in the article's Creative Commons licence, unless indicated otherwise in a credit line to the material. If material is not included in the article's Creative Commons licence and your intended use is not permitted by statutory regulation or exceeds the permitted use, you will need to obtain permission directly from the copyright holder. To view a copy of this licence, visit http://creativecommons.org/licenses/by/4.0/ The Creative Commons Public Domain Dedication waiver (http://creativecommons.org/publicdomain/zero/1.0/) applies to the data made available in this article, unless otherwise stated in a credit line to the data. 


\section{Introduction}

Manganese (Mn) is one of the occupational and environmental toxicants, although it is an essential trace element for normal physiological functions [1]. At present, high concentration $\mathrm{Mn}$ exposure predominantly occurs from welding fumes, mining and smelting of $\mathrm{Mn}$ ore, drinking-water contaminated with high levels of Mn, air pollution containing the anti-knocking agent methylcyclopentadienyl Mn tricarbonyl (MTM), or manganic insecticide and ephedron (a psychostimulant drug) abusers [2-5]. Some studies have shown that excessive Mn exposure can injure the globus pallidus, cortex, striatum, subthalamic nucleus, etc. [6, 7]. Excessive Mn accumulated in the basal ganglia may induce extrapyramidal motor dysfunction, leading to manganism, which shares similar clinical symptoms with Parkinson's disease (PD) $[8,9]$. Microglia, the primary innate immune monitors in the central nervous system (CNS), make up 10-15\% of nerve cells in the CNS under normal conditions [10]. It is primarily involved in maintaining the normal homeostasis of CNS by producing anti-inflammatory and neurotropic factors etc. [11]. Once environmental exotoxins excessively activate microglia, the balance between its protection and pro-inflammatory effects is interrupted [12]. Significantly, excessive Mn exposure or its combination with lipopolysaccharide (LPS) may induce the activation of microglial cells, which then causes neuroinflammation via promoting the secretion of cytotoxic mediators, such as interleukin-1 $\beta$ (IL-1 $\beta$ ) and reactive oxygen species (ROS) [13, 14].

It is well known that NLRP3, a NOD-like receptor and a crucial tissue-damage activator of sterile inflammation, can be activated by diverse damage-associated molecular patterns (DAMPs), such as ROS, mtDNA, ATP, and mitochondrial dysfunction [15]. The activated NLRP3 is assembled into a typical inflammatory complex, called as NLRP3 inflammasome which can recruit pro-caspase-1 [16]. The pro-caspase-1 is transferred to cleaved caspase- 1 in an autocatalytic process which could regulate the activation of gasdermin D (GSDMD) [15, 17]. GSDMD is activated by cleaved caspase-1, thus exposes its N-terminal domain. It then oligomerizes with 16symmetric protomer in membranes to form pores resulting in pyroptosis and IL-1 $\beta$ and IL-18 secretion [18-20]. Pyroptosis, a pro-inflammatory and caspase-1-dependent programmed cell death, has been shown to be associated with heavy metal-induced neurotoxicity via the mediation of the NLRP3-caspase-1 inflammasome or other inflammasomes [21-23]. For instance, an in vitro study showed that cadmium exposure induced NLRP3 inflammasome-dependent pyroptosis by mediating the mitochondrial ROS in human umbilical vein endothelial cells [21]. Moreover, Pei et al. demonstrated that the regulation of endoplasmic reticulum stress on NLRP3- inflammasome-dependent pyroptosis points to a critical pathogenic cause for arsenic-induced pancreatic $\beta$ cells dysfunction [22]. Additionally, various studies indicated that $\mathrm{Mn}$ might induce neuroinflammation by impairing mitochondrial dynamics and modulating MAPK, COX2, NF- $\mathrm{B}$ pathways or NLRP3-CASP1 pathways [24-28]. Significantly, the activation of microglia and NLRP3 inflammasome may be involved in Mn-induced inflammation [9, 14, 29], and ROS may activate the NLRP3 inflammasome [30, 31]. However, whether NLRP3 inflammasome-dependent pyroptosis participates in Mnmediated neuroinflammation is rarely reported.

Clinically, EDTA chelation is commonly used to treat heavy metal poisoning. In the case of manganism patients, symptoms are only slightly improved with EDTA chelation; symptoms soon return after chelation treatment is suspended [32]. Interestingly, clinical data showed that sodium p-aminosalicylic acid (PAS-Na) has a curative effect on manganism patients $[3,33]$. PAS-Na and its metabolites can cross the blood-brain barrier to play a therapeutic effect, while EDTA cannot pass it and limit its therapeutic effects [32, 34]. In vitro studies have confirmed that PAS-Na treatment increased the activity of antioxidant enzymes in Mn-treated primary basal ganglia [35] or hippocampal neurons [36]. Furthermore, results of an in vivo study indicated that PAS-Na would alleviate Mn-induced inflammation [25, 32, 37]. However, its positive effect on the treatment of $\mathrm{Mn}$-induced neuroinflammation needs to be further explored. Therefore, the present study aims to explore the impact of PAS-Na on Mn-induced NLRP3-caspase-1 inflammasome-dependent pyroptosis, combining between in vitro and in vivo studies. We find that Mn can trigger neurotoxicity particularly by oxidative stress, NF- $\mathrm{B}$ pathway activation and NLRP3 inflammasome-dependent pyroptosis. PAS-Na can restore Mn-induced activation of NLRP3 inflammasomedependent pyroptosis by inhibiting NF- $\mathrm{B}$ pathway activation and oxidative stress.

\section{Materials and methods \\ Animals and experimental design}

Male Sprague-Dawley (SD) rats (aged 6 weeks, weighted $130 \pm 20 \mathrm{~g}$ ), specific pathogen-free (SPF), were purchased from the Experimental Animal Center of Guangxi Medical University (SCXKG2014-0002). All animal procedures performed in this study were performed strictly according to the international standards of animal care guidelines and have been authorized by the Animal Care and Use Committee of Guangxi Medical University. The rats were housed under a constant environment (keeping constant temperature and humidity, light/dark cycle) with food and water ad libitum. After being fed adaptively for 1 week, the animals were randomly divided into 8-week and 14-week experimental 
periods. The former included control, low (L)-Mn, medium (M)-Mn, and high (H)-Mn-treated groups with 12 rats per group. And rats were injected intraperitoneally (i.p.) with either $\mathrm{MnCl}_{2} \cdot 4 \mathrm{H}_{2} \mathrm{O}$ (5, 10, and $20 \mathrm{mg} / \mathrm{kg}$, in saline) or saline $(0.9 \% \mathrm{NaCl})$ once a day, 5 days per week, based on a published protocol [32]. The latter included control, Mn-treated, Mn+ Low (L)-PAS, Mn+ Medium (M)-PAS, $\mathrm{Mn}+$ High (H)-PAS and PAS-Na control (C-PAS) groups with 12 rats per group. The rats in the Mn-treated group, Mn + L-PAS, Mn + M-PAS, and $\mathrm{Mn}+\mathrm{H}-\mathrm{PAS}$ received i.p. injection with $20 \mathrm{mg} / \mathrm{kg}$ $\mathrm{MnCl}_{2} \cdot 4 \mathrm{H}_{2} \mathrm{O}$ once a day, 5 days per week for 8 weeks, while rats in the control and C-PAS groups received i.p. injection with saline. Then, rats in the Mn + L-PAS, Mn + M-PAS, and Mn + H-PAS and C-PAS groups received subcutaneously (s.c.) injection with 100, 200, 300, and $300 \mathrm{mg} / \mathrm{kg}$ PAS-Na, respectively, once a day, 5 days per week for next 6 weeks, while rats in other groups received s.c. injection with saline, based on our previous studies [25, 32]. After Morris water maze test, the rats were anesthetized by i.p. injection of $3.5 \%$ chloral hydrate $(10 \mathrm{~mL} / \mathrm{kg})$ and sacrificed. The brain was quickly extracted, and the basal ganglia were collected.

\section{Morris water maze test}

The learning and memory ability of the treated rats was assessed by Morris water maze test and performed according to established protocols from previous studies $[25,38]$. Briefly, the test consists of two parts: training trials for 5 days and spatial probe trials for 1 day. Firstly, the rats entered the water from the east, south, west and north of the Morris water maze to find the platform, respectively. The total swimming distances and escape latency were recorded. If the platform was not found at 90 $\mathrm{s}$, the rat would be guided to the platform. After training trials, the platform was removed for the later trials. The number of rats crossing the platform and swimming speed within $120 \mathrm{~s}$ was recorded.

\section{Immunohistochemistry}

The specific operation steps of immunohistochemistry refer to our previous research [25]. Rabbit anti-CD11b $(0.75 \mu \mathrm{g} / \mathrm{mL}$, Thermo, PA5-79532) was used in this tests.

\section{Immunofluorescence}

The sample process is the same as the previous study [25]. Sections were incubated with the following primary antibody at $4{ }^{\circ} \mathrm{C}$ overnight: rabbit anti-GSDMS antibody (1:500, abcam, ab219800), mouse anti-IBA1 (1:200, Servicebio, GB12105, China). The sections were then washed with PBS and incubated with anti-rabbit IgG [1: 1000, Alexa Fluor ${ }^{\circ} 488$ Conjugate, Cell Signaling Technology (CST), \#4412S] and Anti-mouse IgG (1:1000,
Alexa Fluor 594 Conjugate, CST, \#8890) for $1 \mathrm{~h}$ at room temperature. Lastly, the sections were examined under the EVOS fluorescence microscopy imaging system.

\section{Cell culture}

BV2 cells, a type of microglial cell line, were obtained from the China Center for Type Culture Collection (CCTCC). Cells were placed on T25 flasks and cultured in the culture medium which contains $10 \%$ fetal bovine serum (FBS, Gibco, USA), $100 \mathrm{IU} / \mathrm{mL}$ penicillin, and 100 $\mu \mathrm{g} / \mathrm{mL}$ streptomycin and DMEM/F12. Cells were cultured in a humidified incubator (ThermoScientific, USA) of $5 \% \mathrm{CO} 2$ at $37^{\circ} \mathrm{C}$. The BV2 cells morphology were observed with an inverted microscope (OLYMPUS, Japan)

\section{Measurement of ROS}

BV2 cells were treated with $10 \mu \mathrm{mol} / \mathrm{L} 2^{\prime}, 7^{\prime}$-dichlorodihydrofluorescein dictate (DCFH-DA, Beyotime, China) for $1 \mathrm{~h}$ at $37{ }^{\circ} \mathrm{C}$ in the dark. The detection was performed in strict accordance with the manufacturer's instructions and previous studies [39, 40]. The fluorescence was visualized by using the EVOS fluorescence microscopy imaging system (Thermo, USA).

Flow cytometry was used to detect ROS production. Firstly, BV2 cells were collected into $15 \mathrm{~mL}$ centrifuge tubes and incubated with $10 \mu \mathrm{mol} / \mathrm{L}$ DCFH-DA at $37^{\circ} \mathrm{C}$ in the dark for $1 \mathrm{~h}$ (mixing cells every $10 \mathrm{~min}$ ). Subsequently, cells were re-suspended in pre-cooled PBS, washed in pre-cooled PBS three times, and then transferred to $1.5 \mathrm{~mL}$ EP tubes for detection by flow cytometry.

Detection of mitochondrial membrane potential $\left(\mathrm{mt} \Delta \Psi_{\mathrm{m}}\right)$ Mt $\Delta \Psi \mathrm{m}$ was determined by the lipophilic cationic probe JC-1 (Beyotime, China). At the end of treatment, BV2 cells were treated with $10 \mu \mathrm{g} / \mathrm{ml} \mathrm{JC}-1$ at $37{ }^{\circ} \mathrm{C}$ in the dark for $30 \mathrm{~min}$. The detection was performed in strict accordance with the manufacturer's instructions and previous studies [41, 42]. The fluorescence was visualized by using the EVOS fluorescence microscopy imaging system.

Flow cytometry was used to detect $\mathrm{mt} \Delta \Psi \mathrm{m}$ changes. Firstly, BV2 cells were collected into $15 \mathrm{~mL}$ centrifuge tubes and treated with $10 \mu \mathrm{g} / \mathrm{ml} \mathrm{JC}-1$ at $37{ }^{\circ} \mathrm{C}$ in the dark for $30 \mathrm{~min}$ (mixing cells every $10 \mathrm{~min}$ ). Subsequently, cells were resuspended in staining buffer and detected by flow cytometry after being washed with precooled PBS three times.

\section{Adenosine triphosphate (ATP) assay}

ATP kit (Nanjing Jiancheng Bioengineering Institute, China) was used to assess the intracellular ATP in BV2 cells. Cells were collected and resuspended in boiled 
PBS. The cells were lysed using an ultrasonic pulverizer. The detection was performed in strict accordance with the manufacturer's instructions [43]. Protein levels were detected to normalize the results by using the BCA protein assay kit (Multi Sciences, China).

\section{Lactate dehydrogenase (LDH) assay}

$\mathrm{LDH}$, an indicator of cell membrane integrity, has been shown to indirectly relate to the occurrence of pyroptosis [44]. For this assay, the culture medium was collected and centrifuged at $2500 \times g, 4{ }^{\circ} \mathrm{C}$ for $10 \mathrm{~min}$. Then, the supernatant was transferred into $1.5 \mathrm{~mL}$ EP tubes. $\mathrm{LDH}$ releases in culture medium were detected using LDH kit (Nanjing Jiancheng Bioengineering Institute, China) strictly according to the manufacturer's instructions. Detailed steps was performed the same as our previous study [35]. Protein levels were detected to normalize the results by using the BCA protein assay kit (Multi Sciences, China).

\section{Enzyme-linked immunosorbent assay (ELISA)}

The cell culture medium were collected and centrifuged at $12000 \mathrm{rpm}$ for $5 \mathrm{~min}$. The supernatants were transferred to clean $1.5 \mathrm{~mL}$ EP tubes and stored at $-80{ }^{\circ} \mathrm{C}$. IL-1 $\beta$ and IL-18 levels in the cell culture medium were measured by ELISA kits (Multi Sciences, China) strictly according to the manufacturer's instruction [45].

Total protein in the prefrontal cortex, hippocampus were extracted by using lysis buffer which contains RIPA buffer (CWBIO, China), protease inhibitor (Roche, USA). IL-1 $\beta$ and IL-18 levels in these samples were measured by ELISA kits (Elabscience, China) strictly according to the manufacturer's instruction and previous studies [46, 47]. Protein levels were detected to normalize the results by using $\mathrm{BCA}$ protein assay kit.

\section{Quantitative real-time PCR (qPCR)}

Total RNA was isolated from BV2 cells by using a total RNA extraction kit (Promega, China) according to the manufacturer's protocol. RNA $(1 \mu \mathrm{g})$ was reverse transcribed into cDNA using a reverse transcription kit (Promega, USA). Subsequently, the qPCR amplification was performed using $2 \mu \mathrm{L}$ of cDNA and real-time Fluorescence quantitative PCR instrument (Applied Biosystems, USA) according to the manufacturer's protocol (Promega, USA). Cycling condition: Stage $1: 95{ }^{\circ} \mathrm{C}, 10 \mathrm{~min}$; Stage $2: 95{ }^{\circ} \mathrm{C}, 15 \mathrm{~s}, 60{ }^{\circ} \mathrm{C}, 1 \mathrm{~min}, 40$ cycles; dissociation stage: $95{ }^{\circ} \mathrm{C}, 15 \mathrm{~s}, 60{ }^{\circ} \mathrm{C}, 15 \mathrm{~s}, 95{ }^{\circ} \mathrm{C}, 15 \mathrm{~s}$. The fold change of each gene expression relative to $\beta$-actin was determined by the comparative threshold cycle method. Primer sequences (Sangon Biotech, China) are listed in Table 1.
Table 1 Primer sequences used in the $\mathrm{qPCR}$

\begin{tabular}{ll}
\hline Gene & Primer sequences \\
\hline IL-1 $\beta$ & Forward:5'-CCAGGATGAGGACATGAGCA-3' \\
& Reverse:5'-CGGAGCCTGTAGTGCAGTTG-3' \\
IL-18 & Forward:5'-GACTCTTGCGTCAACTTCAAGG-3' \\
& Reverse:5'-GTTGTCTGATTCCAGGTCTCCA-3' \\
B-actin & Forward:5'-GTGCTATGTTGCTCTAGACTTCG-3' \\
& Reverse:5'-ATGCCACAGGATTCCATACC-3' \\
\hline
\end{tabular}

\section{Western blot}

Total protein in the basal ganglia, prefrontal cortex, hippocampus, and BV2 cells were extracted by using lysis buffer which contains RIPA buffer (CWBIO, China), protease inhibitor (Roche, USA), and phosphatase inhibitor (Roche, USA). BCA protein assay kit was used to detect the protein levels of all samples. The protein samples $(30 \mu \mathrm{g})$ were separated by $6-12 \%$ sodium dodecyl sulfate-polyacrylamide (SDS-PAGE) and transferred to a polyvinylidene fluoride (PVDF) membrane $(0.22 \mu \mathrm{m}$, Roche, USA). After blocking with $5 \%$ bovine serum albumin (Beyotime, China) for $1 \mathrm{~h}$, the membranes were incubated with primary antibodies at $4{ }^{\circ} \mathrm{C}$ overnight. The antibodies be used in the present study are listed as follows: Rabbit anti- $\beta$-actin (CST, \#4970), Rabbit anti-GAPDH (CST, \#5174), Rabbit anti-cleaved caspase1(CST, \#67314), Rabbit anti-NLRP3 (abcam, ab210491), Rabbit anti-p65 (CST, \#8242), Rabbit antiphosphorylation of p65 (p-p65) (CST, \#3033), Mouse anti-IкB (CST, \#4814), Rabbit anti-phosphorylation of ІкB (p-ІкB) (CST, \#2859), Rabbit anti-IL-1ß (abcam, ab9722), Rabbit anti-IL-18 (abcam, 191860), and Rabbit antiCD11b (Thermo, PA5-79532). Subsequently, the membranes were washed with TBST and incubated with antirabbit IgG (CST, \#7074) or anti-mouse IgG (CST, \#7076) at room temperature for $1 \mathrm{~h}$. Finally, protein bands were visualized by using an enhanced chemiluminescence system (Thermo, USA) and qualified using Image J.

\section{Statistical analysis}

All data were presented as the mean \pm S.D. and analyzed using SPSS statistical software (version 23.0, IBM). Repeated one-way analysis of variance (ANOVA) was used to analyze the results of the Morris water maze test. Other data was analyzed by one-way analysis of variance. ANOVA followed by least significant difference (LSD) tests was used for multiple comparisons. The Games-Howell correction test was used, when equal variance not assumed. Statistical significances were considered as $p$ values $<0.05$.

\section{Results}

PAS-Na enhances the learning ability of Mn-exposed rats Accumulation of $\mathrm{Mn}$ in the brain could cause neurological dysfunction, including learning and memory 
disorders, bradykinesia, etc. Our previous study showed that $\mathrm{Mn}$ levels in the striatum and globus pallidus of rats were dramatically increased after $15 \mathrm{mg} / \mathrm{kg} \mathrm{MnCl}_{2}$ treatment for 3 weeks compared to the control group (1.53 \pm 0.04 vs $0.92 \pm 0.02$ and $1.47 \pm 0.03$ vs $0.87 \pm 0.07$, respectively) [48]. To make the behavioral changes induced by Mn valid, rats were applied in this study and the learning and memory capacity were tested using Morris water maze. The escaping latency and swimming distance of $\mathrm{Mn}$-exposed rats were significantly increased after exposure to $\mathrm{MnCl}_{2}$ for 8 weeks compared to the control group ( $p<0.05$ or 0.01 , Fig. 1a, b). The swimming distance still increased after exposure to $20 \mathrm{mg} / \mathrm{kg} \mathrm{MnCl}_{2}$ for 8 weeks and followed by 6 weeks of no Mn exposure $(p<0.01$, Fig. 1e). After treatment with PAS-Na, the swimming distances were shorter on the 2nd and 5th training days compared to the Mn-exposed group ( $p<0.05$ or 0.01 , Fig. 1e). However, the frequency difference of probe times between the Mn-treated group and the control group was not significant $(p>0.05$, Fig. $1 \mathrm{c}, \mathrm{f})$.

PAS-Na inhibits Mn-induced oxidative stress in BV2 cells To detect the oxidative damage caused by $\mathrm{Mn}$ and the protective effect of PAS-Na, we measured ROS production, $\mathrm{mt} \triangle \Psi \mathrm{m}$ changes and ATP levels in BV2 cells, using NAC (an antioxidant, Beyotime, China) as a positive control [49]. The fluorescent images showed that ROS levels in all doses of Mn-treated groups were higher than those in the controls (Fig. 2a). Besides, after BV2 cells were treated with $\mathrm{Mn}$ for $24 \mathrm{~h}$, the $\mathrm{mt} \Delta \Psi \mathrm{m}$ of cells decreased significantly, compared to the control group (Fig. 2b). ATP production was also decreased in the 200 and $400 \mu \mathrm{mol} / \mathrm{L} \mathrm{Mn-treated} \mathrm{groups}(p<0.01$, Fig.2c), which might be due to the decrease of $m t \Delta \Psi \mathrm{m}$ and blocked electron transport. However, PAS-Na and NAC treatment decreased the intracellular ROS and recovered the loss of $\mathrm{mt} \Delta \Psi \mathrm{m}$ in Mn-treated BV2 cells compared to the Mn-treated group ( $p<0.05$ or $p<0.01$, Fig. 2e, $\mathrm{f}$ ). Subsequently, ATP levels in the Mn-treated BV2 cells were recovered as compared with the Mn-treated group ( $p<0.05$ or $p<0.01$, Fig. 2d). Administration of PAS$\mathrm{Na}$ and NAC alone has no effects on the intracellular ROS, $\mathrm{mt} \Delta \Psi \mathrm{m}$, and ATP in BV2 cells ( $p>0.05$, Fig. $2 \mathrm{~d}-\mathrm{f})$. Our previous study confirmed that PAS-Na could inhibit $\mathrm{Mn}$-induced oxidative stress by increasing the activity of primary anti-oxidant enzymes glutathione peroxidase (GSH-Px) and catalase (CAT) [35]. These results indicated that PAS-Na could effectively resist the oxidative damage caused by Mn.

\section{PAS-Na inhibits Mn-induced NF-KB pathway activation by suppressing oxidative stress in BV2 cells}

Oxidative stress can activate inflammatory pathways such as NF-kB, causing inflammation. NAC and JSH-23

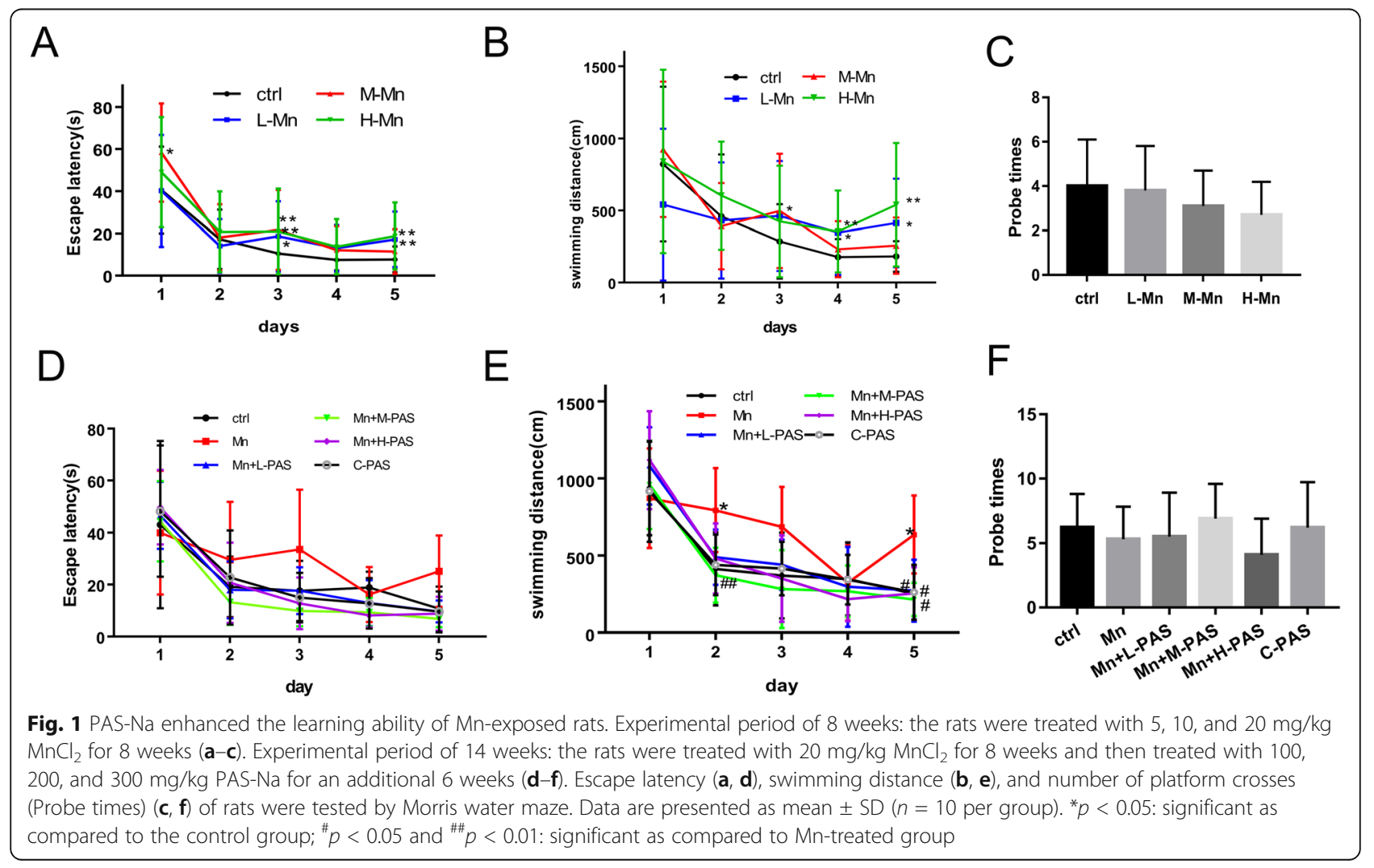




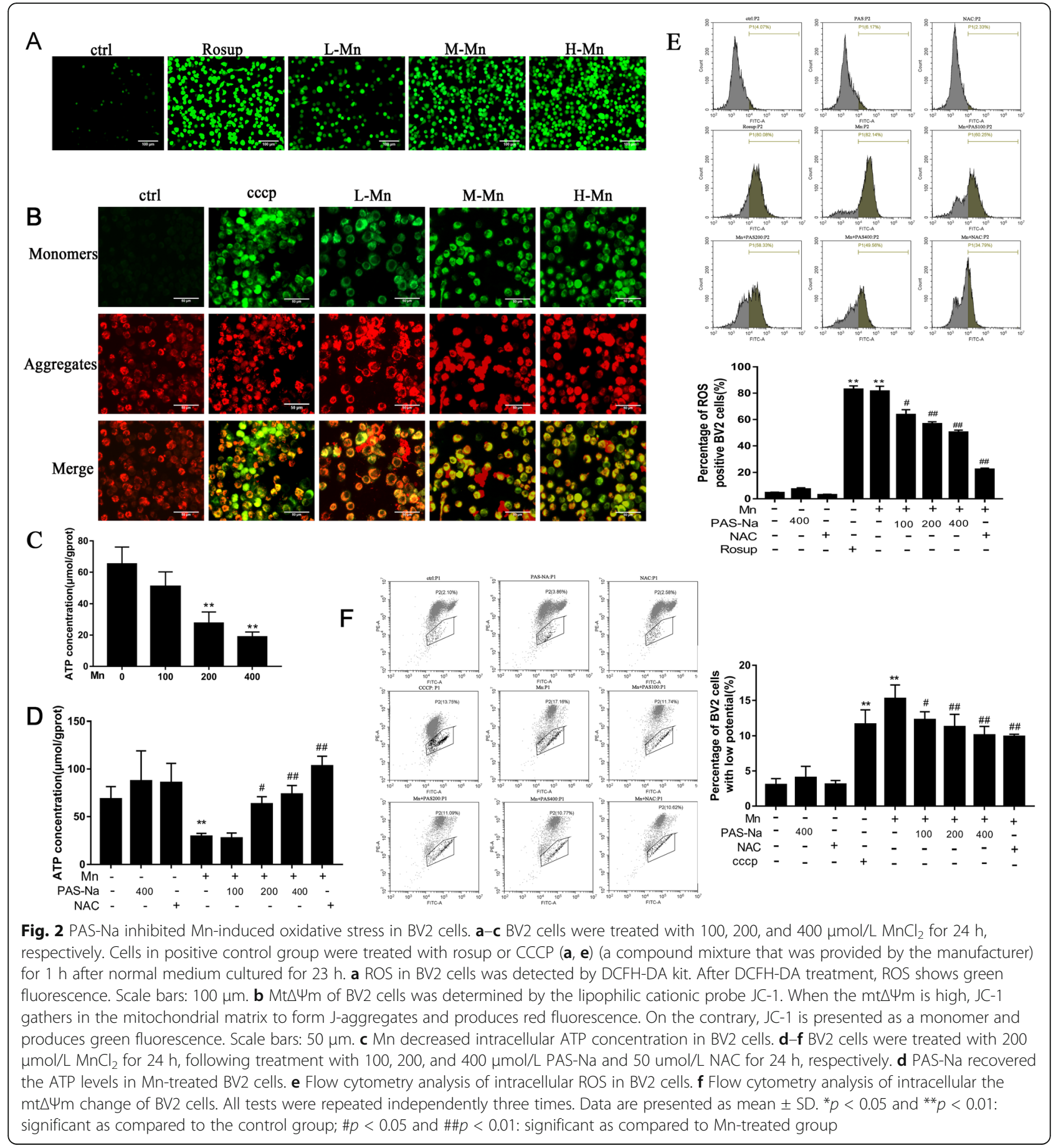

(an inhibitor of transcriptional activity of NF- $\mathrm{kB}$, Selleck Chemicals, USA) were used here. As shown in Fig. 3a, Mn-treated BV2 cells had fewer branches and cell membrane was destroyed, displayed a typical feature of pyroptosis membrane rupture [50]. As the Mn treatment dose increases, this morphological change becomes more severe. We also found that Mn could activate the NF- $\mathrm{kB}$ pathway by increasing the phosphorylation of p65 and IkB- $\alpha$ in BV2 cells (Fig. 3b). Next, we explored whether
PAS-Na could attenuate the activation of NF- $\mathrm{kB}$ pathway by inhibiting oxidative stress. PAS-Na and NAC treatment clearly restored cell morphology as compared with the Mn-treated group (Fig. 3c). Addition of PAS$\mathrm{Na}$ and NAC alone hardly affected BV2 cell morphology. However, PAS-Na reduces the p-p65 and P-IкB- $\alpha$ caused by $\mathrm{Mn}$, and its effect is similar to NAC, especially the phosphorylation of p65 when treated with $100 \mu \mathrm{mol} /$ LPAS-Na and ІкB- $\alpha$ when treated with $200 \mu \mathrm{mol} / \mathrm{LPAS}$ - 


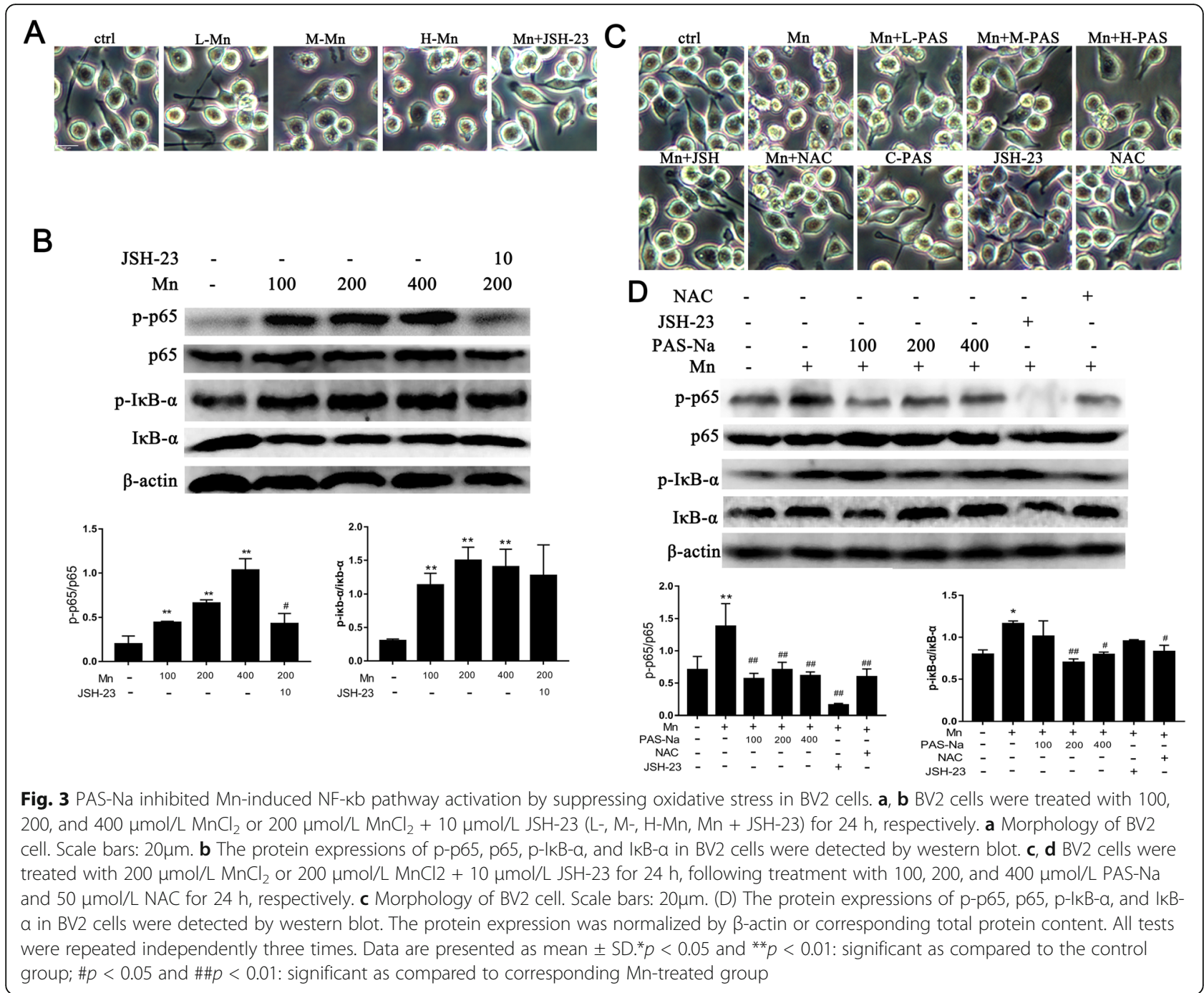

$\mathrm{Na}(p<0.05$ or $p<0.01$, Fig. 3d). Collectively, this confirmed that PAS-Na could inhibit the activation of NF$\kappa \mathrm{B}$ by inhibiting $\mathrm{Mn}$-induced oxidative stress.

PAS-Na mitigates Mn-induced BV2 cells activation and microglia proliferation by inhibiting NF-KB pathway activation In order to clarify the connections among Mn-induced microglia activation, NF-kB pathway and the effect of PAS-Na intervention, we used JSH-23 as a positive control [51]. Our results showed that P65 could enter the nucleus in Mn-treated BV2 cells, which can be inhibited by JSH23 (Figure S1). The expression of p-p65 and p-IкB- $\alpha$ in Mn-treated BV2 cells (Fig. 3b) and in the basal ganglia of Mn-exposed rats were significantly increased $(p<0.05$ or $p<0.01$, Fig. 4b). Nonetheless, as compared with the Mntreated group, the expression of p-p65 in PAS-Na treatment groups and JSH-23 treatment group were significantly decreased, while the decrease in JSH-23 treatment was more robust $(p<0.01$, Fig. 3d). Different doses of
PAS-Na and JSH-23 treatment also restored cell morphology as compared with the Mn-treated group (Fig. 3c), while the JSH-23 alone hardly affected. This data suggested the specificity of PAS-Na in protecting $\mathrm{Mn}$ induced toxicity. CD11b is specifically expressed in microglia of brain which often used to identify activated microglia [52-54]. The protein expression of CD11b in the basal ganglia of rats was significantly increased after exposure to 10 and $20 \mathrm{mg} / \mathrm{kg} \mathrm{MnCl}{ }_{2}(p<0.01$, Fig. 4a). Furthermore, we used in vivo studies to further verify our findings and got similar results that the expression of CD11b, p-IкB- $\alpha$, and p-p65 in the basal ganglia of PAS$\mathrm{Na}$ treatment groups were significantly decreased compared to the Mn-exposed group ( $p<0.01$, Fig. $4 \mathrm{c}$, e, respectively). And p-p65 in the prefrontal cortex and hippocampus of PAS-Na treatment groups were significantly decreased compared to the Mn-exposed group ( $p<$ 0.001, Fig. 7a). Besides, compared with the Mn-exposed group, immunohistochemical results of CD11b showed that 


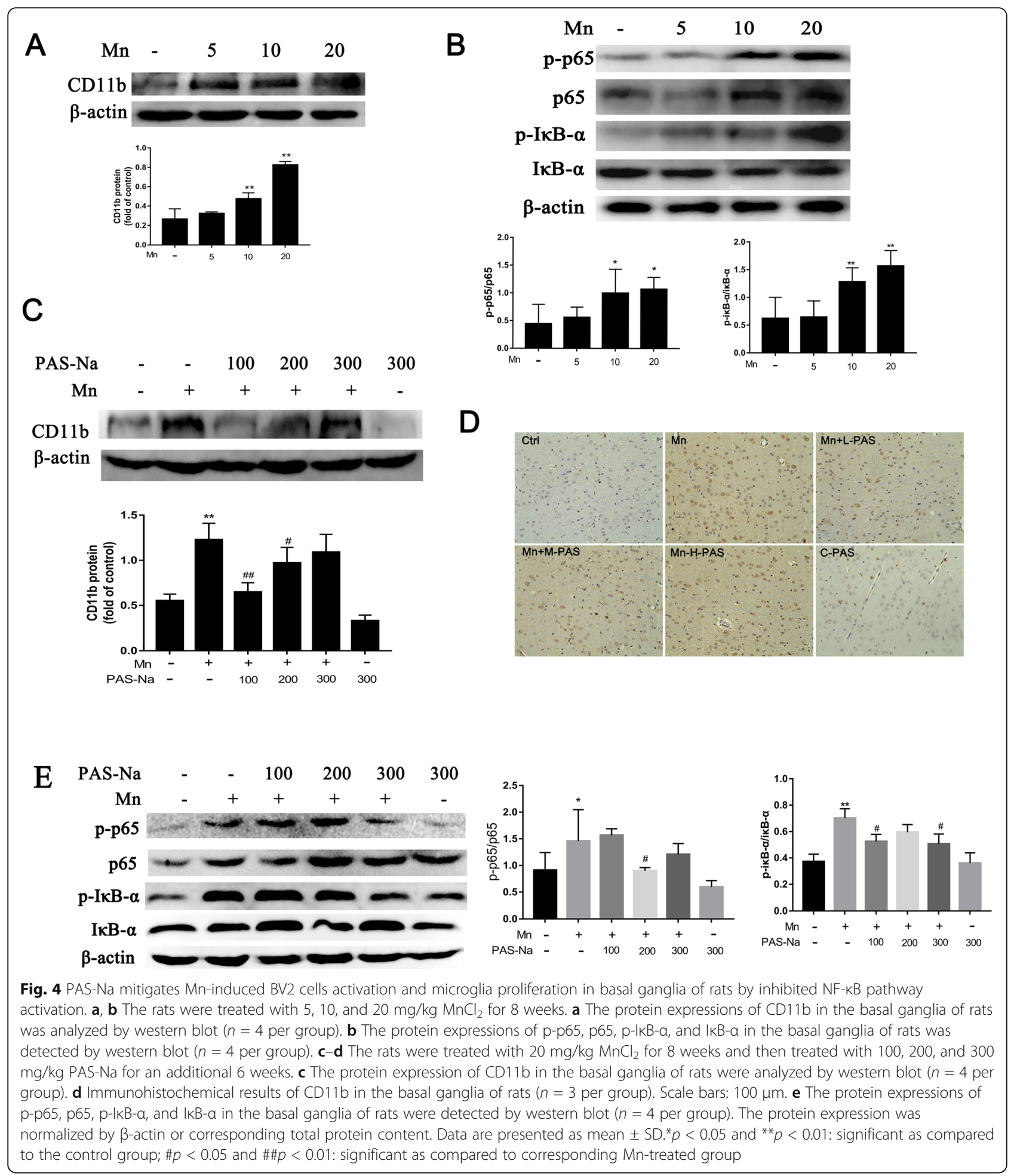

the number of CD11b-positive cells was significantly reduced after PAS-Na intervention, especially in the $\mathrm{Mn}+\mathrm{L}$ PAS and Mn + M-PAS groups (Fig. 4d). These results indicated that PAS-Na might alleviate Mn-induced BV2 cells activation and microglia proliferation in basal ganglia of rats by inhibiting the activation NF-kB pathway.
PAS-Na inhibits Mn-induced NLRP3 inflammasomedependent pyroptosis by inhibiting NF-KB pathway activation and oxidative stress

To investigate whether PAS-Na inhibits Mn-induced NLRP3 inflammasome-dependent pyroptosis, in vitro and in vivo studies were conducted simultaneously. 
Measurement of LDH release was performed to assess the pyroptosis (Schneider et al. 2017). Mn treatment increased the LDH release in culture medium in a dosedependent manner, as compared with the control $(r=$ 0.952, $p<0.05$, Fig. 5a). ROS and mitochondrial dysfunction can activate NLRP3. In this study, the expression of NLRP3 and cleaved caspase-1(Cleaved CASP1) were significantly increased after Mn treatment in BV2 cells and in the basal ganglia of rats $(p<0.05$ and $p<$ 0.01 , respectively, Fig. $5 \mathrm{~b}, \mathrm{~d}$ ). Concomitantly, both the IL- $1 \beta$ and IL-18 mRNA and their secretion levels in Mn-treated BV2cells or culture medium were increased dramatically compared to control ( $p<0.01$, Fig. $5 c)$. The IL-1 $\beta$ and IL-18 protein expression was also significantly increased in the basal ganglia of Mn-exposed rats as compared with those in control ( $p<0.01$, Fig. 5 d). However, LDH relative release, the expression of NLRP3 and cleaved CASP1 protein and both the mRNA and secreted protein of IL-1 $\beta$ and IL-18 level were significantly reduced in JSH-23 treatment groups compared to the corresponding Mn-treated group $(p<0.05$ and $p<0.01$, respectively, Fig. $5 \mathrm{a}-\mathrm{c}$ ), which implied that NF- $\mathrm{kB}$ played a crucial role in NLRP3 inflammasome-dependent pyroptosis.

As the above results confirmed that PAS-Na could inhibit $\mathrm{Mn}$-induced oxidative stress and NF- $\mathrm{kB}$ activation, we further investigated whether it could prevent Mninduced NLRP3 inflammasome-dependent pyroptosis. After treatment with PAS-Na for $24 \mathrm{~h}$, the relative release of LDH (Fig. 6c) and the secretion of IL-1 $\beta$ (Fig.

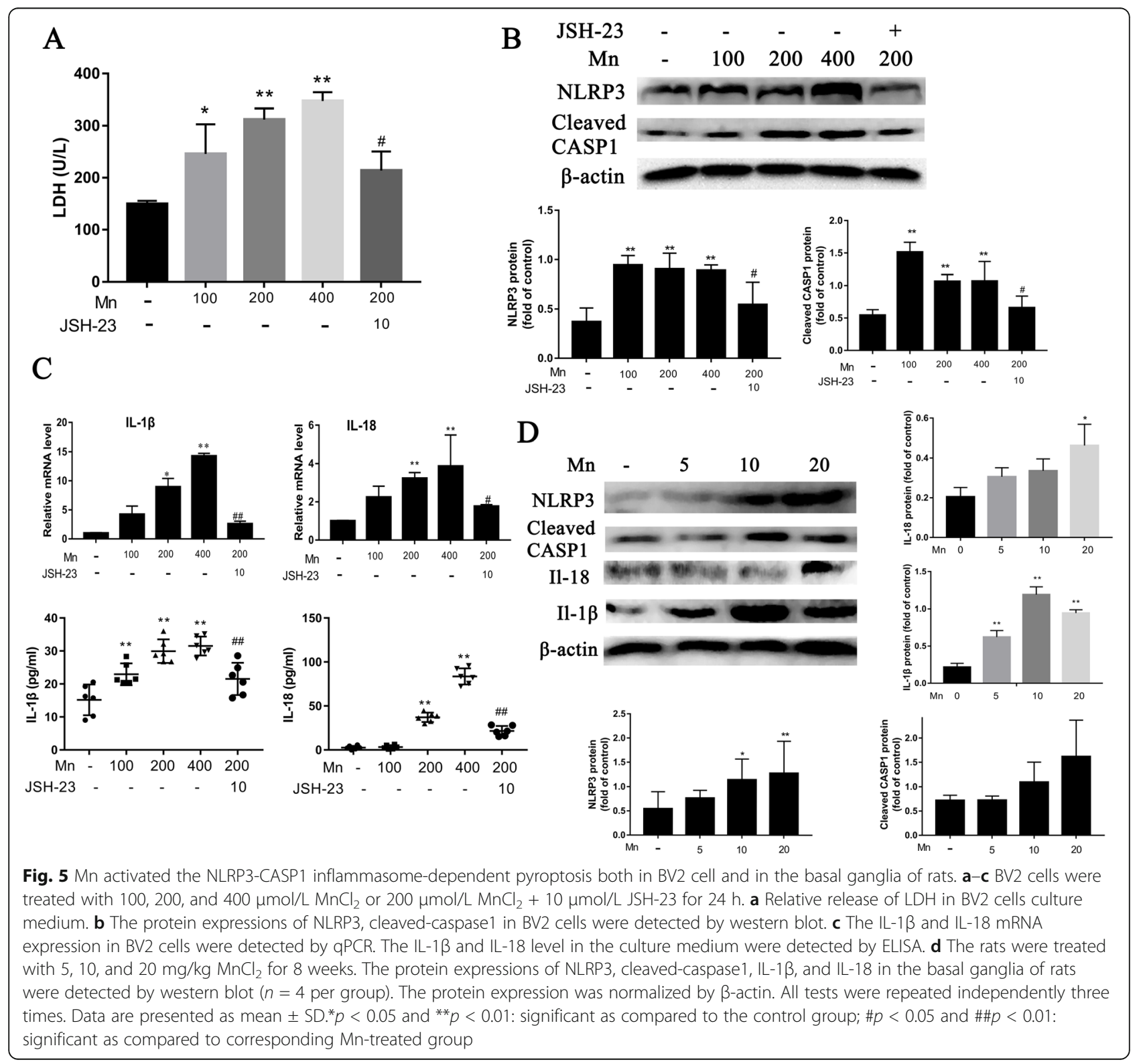


$6 \mathrm{~b})$ in the medium also decreased significantly. The expression of NLRP3 and cleaved CASP1 in the control group markedly decreased as compared to the Mn-treated BV2 cells $(p<0.05$ or $p<0.01$, Fig. 6 a). The decrease in the JSH-23 treatment group was more robust after treatment with JSH-23 ( $p<0.05$ or $p<0.01$, Fig. $6 \mathrm{~b}, \mathrm{c})$. The NLRP3 and cleaved CASP1 expressions in the NAC treatment group also significantly decreased as compared with the Mn-treated group, especially cleared CASP1 $(p<0.01$, Fig. $6 \mathrm{~b}$ ). The relative release of $\mathrm{LDH}$ and the secretion of IL-1 $\beta$ in the medium also had a pronounced decrease after NAC treatment for $24 \mathrm{~h}(p<0.01$, Fig. 6a, c). Moreover, in vivo studies have shown similar results that PAS-Na could antagonize the increase of NLRP3, cleaved CASP1, IL-18, and IL-1 $\beta$ protein expressions induced by $\mathrm{Mn}$ in the basal ganglia ( $p<0.05$ or $p<0.01$, Fig. $6 \mathrm{~d}$ ) and hippocampus $(p<0.05, p<0.01$, or $p<0.001$, Fig. 7a, b) of rats.
The expressions of NLRP3 and cleaved CASP1 did not increase significantly in the prefrontal cortex as compared with the Mn-treated group ( $p>0.05$, Fig. 7a). GSDMD is a pyroptosis effector that is widely used to evaluate the occurrence of pyroptosis (Schneider et al. 2017). In this study, immunofluorescence results showed that Mn treatment increased the number of activated microglia, which stained positively for GSDMD (Fig.6e). However, PAS-Na inhibited this increase (Fig. 6e). These results implied that PAS-Na might inhibit Mn-induced NLRP3 inflammasome-dependent pyroptosis by inhibiting the activation of NF- $\mathrm{B}$ B pathway and oxidative stress.

\section{Discussion}

Excessive exposure to Mn can cause manganism, although $\mathrm{Mn}$ is an essential trace element for the human. As excessive Mn mainly accumulates in the basal

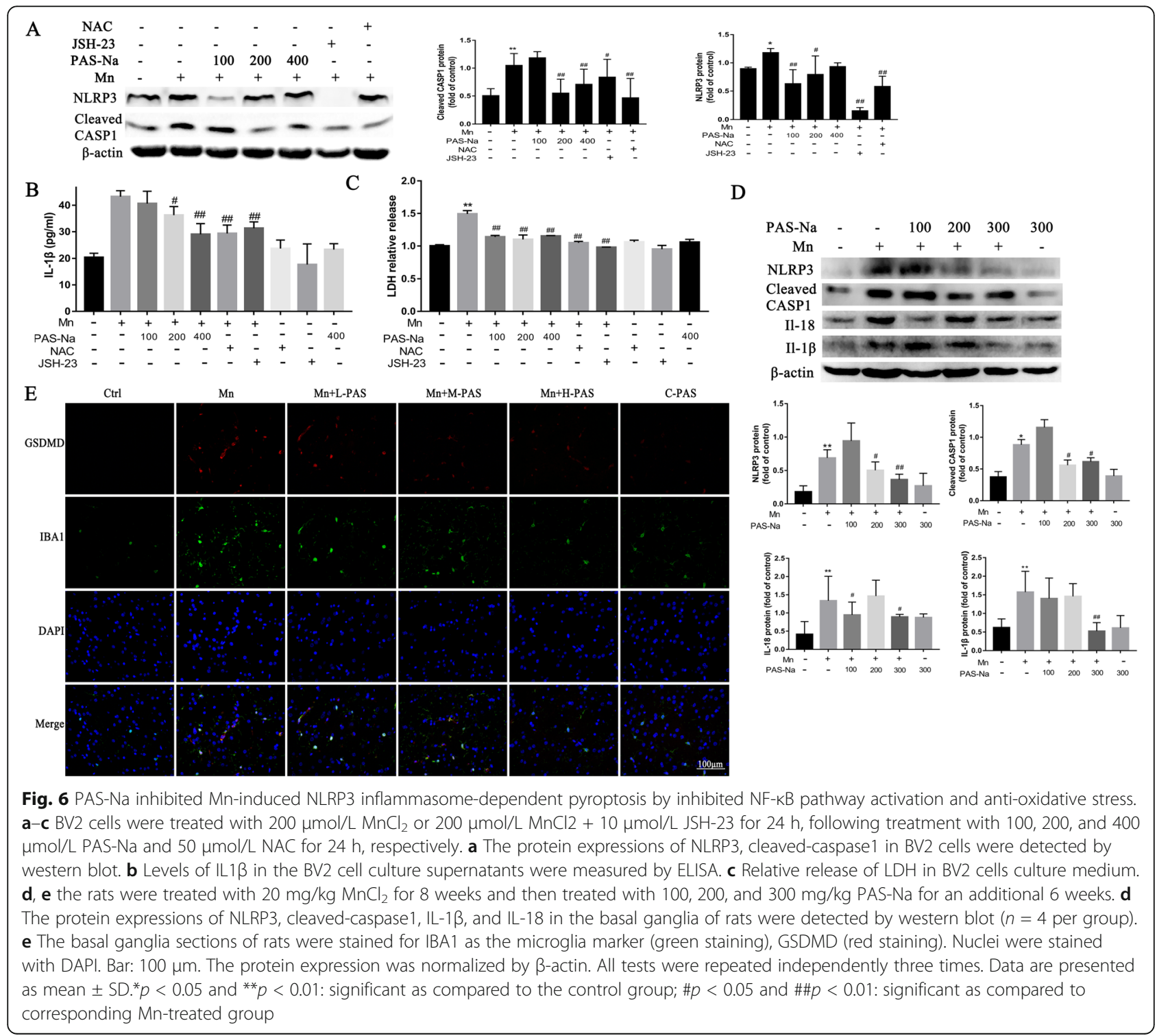




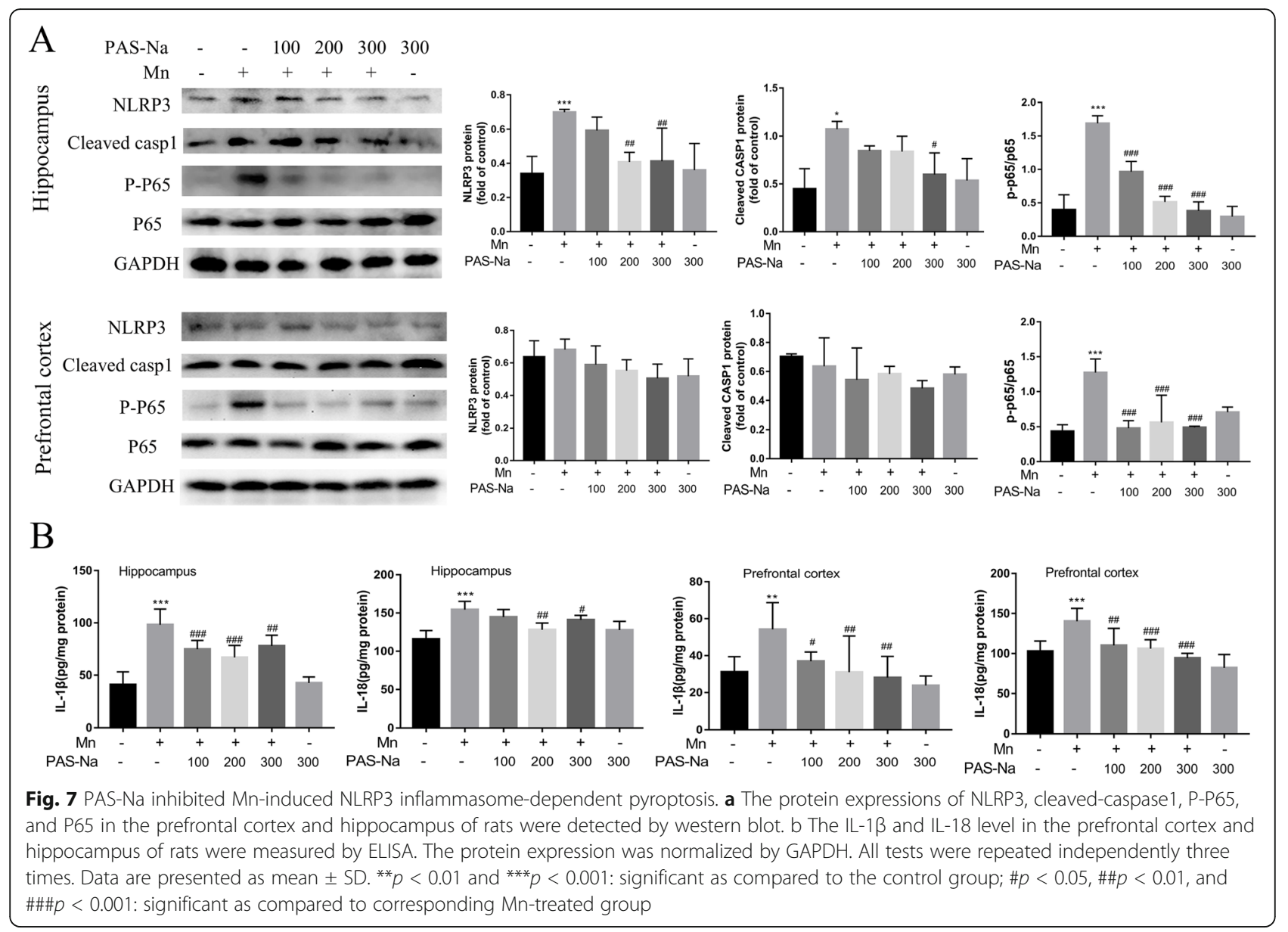

ganglia, Mn poisoning can cause motor and learning disabilities, which shares clinical presentation with Parkinson's disease (PD) [55-57]. Many studies have confirmed that the activation of microglia and NLRP3inflammasome may be involved in Mn-induced inflammation [27, 28]. Our previous studies have shown that PAS-Na can alleviate Mn-induced inflammation [25, 32]. In this study, BV2 cells and male SD rats were used to evaluate whether PAS-Na could attenuate Mn-induced NLRP3 inflammasome-dependent pyroptosis.

Microglia, a type of glial cells that acts as macrophage in the brain, is the first and primary immune defense in the CNS $[58,59]$. Various clinical and neuropathologic studies have shown that the activation of microglial cells is involved in the pathogenesis of neurodegenerative diseases $[44,60,61]$. It is an essential source of proinflammatory factors and oxidative stress, such as TNF, interleukin and other neurotoxic substances [58, 59]. Many studies showed that heavy metals could induce neurotoxicity via activating the microglial cells, especially $\mathrm{Mn}[22,23,62]$. In vitro study demonstrated that $\mathrm{Mn}$ and/or LPS can activate BV2 cells via activating MAP kinase, PI3K/Akt pathways and inflammatory process [63]. As above, we selected BV2 cells for in vitro research. It is worth noting that microglia in the globus pallidus external segment (GPe), and globus pallidus internal segment $(\mathrm{GPi})$ of workers chronically exposed to Mn were increased by $53 \%$ and $38 \%$, respectively, as compared with those in non-Mn exposed workers [7]. An in vivo studies have shown that microglia in the hippocampus of Mn-exposed rats were activated displaying a dramatic change in morphology and staining positively for NLRP3 [28]. Besides, Chronic Mn exposure can result in apoptosis of central nerve cells in rats' hippocampus, and upregulate Hsp70 transcription and translation. Our results show that Mn could promote the activation the NF- $\mathrm{kB}$ inflammation pathway and/or proliferation of microglia and in the basal ganglia, hippocampus and prefrontal cortex of Mn-exposed rats. Therefore, further research on the neurotoxicity of $\mathrm{Mn}$ in microglia and parallel studies on any neuroprotective activity of PAS-Na will be valuable.

Oxidative stress, which refers to the imbalance between ROS and antioxidant functions in the body, plays a critical role in the CNS. Various indicators of oxidative stress have been documented in neurodegenerative 
diseases [64]. Oxidative stress has been shown to participate in Mn-induced neurotoxicity $[65,66]$. For example, excessive $\mathrm{Mn}$ exposure induced oxidative damage by down-regulating the protein expressions of the neuronal excitatory amino acid carrier 1 (EAAC1) and cystine/ glutamate exchanger $(\mathrm{xCT})$ to restrain glutathione synthesis in the striatum of mice [67]. Mitochondria play a pivotal role in normal biological functions by maintaining homeostasis of ATP, metal ions, and ROS [68, 69]. The neurotoxic effects of $\mathrm{Mn}$ interrupt this homeostasis, increasing ROS generation and decreasing the ATP level in BV2 cells. In the normal tricarboxylic acid (ATC) cycle, electrons are transferred to $\mathrm{O}_{2}$ and eventually form $\mathrm{H}_{2} \mathrm{O}$, which is regulated by the redox systems of glutathione. In the process of respiration and oxidation, mitochondria store the energy generated in the inner mitochondrial membrane with electrochemical potential energy, which causes an asymmetric distribution of proton and other ion concentrations on both sides of the inner membrane to form $\mathrm{mt} \Delta \Psi \mathrm{m}[70,71]$. More importantly, protons act through the respiratory enzyme complex to form $\mathrm{H}_{2} \mathrm{O}$ and release ATP in the mitochondria electron transfer chain (ETC) protein complexes [68]. However, mitochondrial damage could lead to the collapse of the $m t \Delta \Psi \mathrm{m}$ and obstacle production [72]. Both the deficiency and excessive accumulations of one or multiple metals may cause mitochondrial dysfunction [73]. In this study, Mn treatment led to the collapse of the $\mathrm{mt} \Delta \Psi \mathrm{m}$, suggesting that the metal balance in the mitochondria was disrupted. Future experiments need to be done to detect metal levels in mitochondria to support this conclusion directly. Research has shown that PAS-Na can inhibit Mn-induced oxidative stress by increasing the activities of primary anti-oxidant enzymes glutathione peroxidase (GSH-Px) and catalase (CAT) (Li et al. 2016). Our results show that PAS-Na could alleviate $\mathrm{Mn}$-induced oxidative stress damage by inhibiting ROS generation, increasing mitochondrial membrane potential and ATP levels. These results indicate that PAS-Na can effectively resist $\mathrm{Mn}$-induced oxidative damage.

NF- $\mathrm{kB}$, a major transcription factor in immune regulation, is widely expressed in biological systems [10]. Inhibitory proteins of the $\kappa b$ family $(\mathrm{I} \kappa \mathrm{B})$ plays a valuable role in regulating the normal balance of NF-kB [10]. The activation of NF- $\kappa B$ induced by phosphorylated $\mathrm{I} \kappa \mathrm{B}$ might interrupt the balance of transcription genes to activate NLRP3 and pro-IL-1 $\beta[15,74]$. An earlier study indicated that the p65 subunit plays a significant role in maintaining the formation of excitatory synapses, dendritic spines, the morphology of mouse hippocampal neurons [75], and astrocytic process plasticity of mouse mediobasal hypothalamus [76]. NF-kB also takes part in regulating the inflammatory response in microglia [77].
Recently, NF- $\mathrm{kB}$ signaling pathway has been shown to play a major role in Mn-induced promotion of inflammatory response and apoptosis. For example, an in vitro study demonstrated that Mn activated NF- $\mathrm{KB}$ by interacting with PI3K/Akt pathway in astrocytes [78] and increased NF- $\mathrm{KB}$ DNA binding activity in PC12 cells [79]. Interestingly, ROS is critical for nuclear reprogramming and the activation of NF- $\mathrm{KB}$ signaling [80, 81]. The present results show that PAS-Na can inhibit $\mathrm{Mn}$ induced NF- $\mathrm{KB}$ activity, which is similar to that of antioxidant NAC. These findings suggest PAS-Na may inhibit Mn-induced NF- $k B$ pathway activation through the suppression of oxidative stress.

Pyroptosis, a new way of programmed cell death, is characterized by reliance on caspase- 1 accompanied by the release of a large amount of pro-inflammatory factors. It is worth noting that pyroptosis is involved in various neurodegenerative diseases [17, 44, 50]. As known, organisms could sense intracellular and extracellular dangerous signals through Nod-like receptors (NLRs) [82]. The NLRs distinguishes the signals and triggers a signaling cascade leading to pyroptosis and the production of inflammatory cytokine [82, 83]. McKenzie et al. reported that the protein expressions of pyroptosis-related genes were elevated in the microglia cells of multiple sclerosis models, including IL-1 $\beta$, IL-18, caspase-1, and NLRP3 [44]. Furthermore, mitochondrial dysfunction and excessive ROS generation always accompanied by PD occurrence and development via NLRP3 inflammasome-dependent pyroptosis, and thus promote the secretion of IL-1 $\beta$ and IL-18 [61]. Wang et al. reported that Mn activated the NLRP3 inflammasome pathway via triggering autophagy dysfunction and promoting the secretion of IL-1 $\beta$ and IL-18 [28]. This study also showed that Mn activated the NLRP3 inflammasome and promoted the secretion of IL- $1 \beta$ and IL- 18 . Excitedly, NF- $\mathrm{kB}$ signaling acts as a priming signal to activate the NLRP3 inflammasome pathway and then promotes the secretion of IL-1 $\beta$ [27]. The activations of the NLRP3 inflammasome relies on the ROS generations $[30,31]$. Therefore, both oxidative stress and NF-kB activation can be therapeutic targets for the neurotoxicity of $\mathrm{Mn}$. PAS-Na is active in the treatment of manganism. Earlier studies showed that PAS-Na increased the antioxidant enzyme activities of glutathione peroxidase and catalase in Mn-treated primary basal ganglia neurons [35]. Further, previous studies demonstrated that PAS-Na decreased IL- $1 \beta$ and TNF- $\alpha$ levels in the serum of Mnexposed rats, as well as the brain E2 prostaglandin (PGE2) levels via modulating MAPK pathway [25, 32, 37]. PAS$\mathrm{Na}$ has been shown to partially reverse the learning and memory dysfunction induced by Mn [25, 84]. The present study showed that PAS-Na could antagonize the increase of NLRP3, cleaved CASP1, IL-18, and IL-1 $\beta$ protein 
expression induced and inhibited the increase of GSDM D-positive cells in the basal ganglia and hippocampus of Mn-exposed rats; the learning ability of these rats was subsequently improved. Summarily, PAS-NA may inhibit Mn-induced NLRP3 inflammasome-dependent pyroptosis by inhibiting NF-kB pathway activation and oxidative stress.

\section{Conclusion}

We provide evidence in this study that exposure to $\mathrm{Mn}$ can result in neurotoxicity particularly through ROS increase, mitochondrial dysfunction, ATP level decrease, NF- $\mathrm{KB}$ pathway activation, and NLRP3 inflammasomedependent pyroptosis occurrence. PAS-Na can attenuate Mn-induced activation of NLRP3 inflammasomedependent pyroptosis by inhibiting NF- $\mathrm{kB}$ pathway activation and oxidative stress. These findings provide insight into the therapeutic mechanisms of PAS-Na on Mn-induced neurotoxicity. Future studies incorporating the long-term exposure of $\mathrm{Mn}$ at environmentally relevant concentrations are desirable to further understand the therapeutic mechanisms of PAS-Na.

\section{Supplementary Information}

The online version contains supplementary material available at https://doi. org/10.1186/s12974-020-02018-6

Additional file 1: Figure S1. Supplement results.

\begin{abstract}
Abbreviations
NLRP3: NOD-like receptor protein 3; PD: Parkinson's disease; CNS: Central nervous system; IL-1 $\beta$ : Interleukin-1 $\beta$; ROS: Reactive oxygen species; DAMPs: Diverse damage-associated molecular patterns; GSDMD: Gasdermin D; PAS-Na: Sodium p-aminosalicylic acid; AD: Alzheimer's disease; MAPK: Mitogen-activated protein kinase; COX-2: Cyclooxygenase-2; NFKB: Nuclear factor-Kappa B; EAAC1: Excitatory amino acid carrier 1; SDSPAGE: Sodium dodecyl sulfate-polyacrylamide; PVDF: Polyvinylidene fluoride membrane
\end{abstract}

\section{Acknowledgements}

We thank assistant professor Pan Chen and Dr. Mahfuzur R. Miah from Albert Einstein College of Medicine for their critical reading and revision of the manuscript before submission.

\section{Authors' contributions \\ Dongjie Peng, Junyan Li and Yue Deng carried out the studies, analyzed the data and drafted the manuscript. Xiaojuan Zhu and Lin Zhao carried out the behavioral tests and data analysis. Yuwen Zhang and Zhaocong Li assisted with the establishment of the rat model. Shiyan Ou took part in the sample preparation. Yueming Jiang acquired Funding. Shaojun Li and Yueming Jiang designed this study and reviewed this manuscript. The authors read and approved the final manuscript.}

\section{Funding}

This study was supported by the grants of the National Natural Science Foundation of China (grant numbers 81460505, 81973094 and 81803281) and the Natural Science Foundation of Guangxi, China (number 2018GXNSFBA050060)

\section{Availability of data and materials}

The datasets during and/or analyzed during the current study are available from the corresponding author on reasonable request.

\section{Ethics approval and consent to participate}

All animal procedures performed in this study were performed strictly according to the international standards of animal care guidelines and have been approved by the Animal Care and Use Committee of Guangxi Medical University.

\section{Consent for publication}

Not applicable.

\section{Competing interests}

There is no conflict of interest with any of the authors. This manuscript has not been published before and is not currently submitted for review to any other journal.

\section{Author details}

'Department of Toxicology, School of Public Health, Guangxi Medical University, Shuang-yong Road No.22, Nanning 530021, Guangxi, China. ${ }^{2}$ Guangxi Colleges and Universities Key Laboratory of Prevention and Control of Highly Prevalent Diseases, Guangxi Medical University, Shuang-yong Road No.22, Nanning 530021, Guangxi, China.

Received: 19 August 2020 Accepted: 29 October 2020

Published online: 17 November 2020

\section{References}

1. Du S, Wu X, Han T, Duan W, Liu L, Qi J, Niu Y, Na L, Sun C. Dietary manganese and type 2 diabetes mellitus: two prospective cohort studies in China. Diabetologia. 2018;61:1985-95.

2. Lu L, Zhang LL, Li GJ, Guo W, Liang W, Zheng W. Alteration of serum concentrations of manganese, iron, ferritin, and transferrin receptor following exposure to welding fumes among career welders. Neurotoxicology. 2005;26:257-65.

3. Jiang YM, Mo XA, Du FQ, Fu X, Zhu XY, Gao HY, Xie JL, Liao FL, Pira E, Zheng $W$. Effective treatment of manganese-induced occupational Parkinsonism with p-aminosalicylic acid: a case of 17-year follow-up study. J Occup Environ Med. 2006:48:644-9.

4. Proudfoot O. Manganese in manganism, Parkinson's disease, Huntington's disease, amyotrophic lateral sclerosis, and Batten disease: A narrative review. Neurol India. 2017;65:1241-7.

5. Guilarte TR. Manganese and Parkinson's disease: a critical review and new findings. Environ Health Perspect. 2010;118:1071-80.

6. Deng Y, Jiao C, Mi C, Xu B, Li Y, Wang F, Liu W, Xu Z. Melatonin inhibits manganese-induced motor dysfunction and neuronal loss in mice: involvement of oxidative stress and dopaminergic neurodegeneration. Mol Neurobiol. 2015;51:68-88.

7. Gonzalez-Cuyar LF, Nelson G, Criswell SR, Ho P, Lonzanida JA, Checkoway H, Seixas N, Gelman BB, Evanoff BA, Murray J, et al. Quantitative neuropathology associated with chronic manganese exposure in South African mine workers. Neurotoxicology. 2014;45:260-6.

8. Johnson J Jr, Pajarillo E, Karki P, Kim J, Son DS, Aschner M, Lee E. Valproic acid attenuates manganese-induced reduction in expression of GLT-1 and GLAST with concomitant changes in murine dopaminergic neurotoxicity. Neurotoxicology. 2018;67:112-20.

9. Kirkley KS, Popichak KA, Afzali MF, Legare ME, Tjalkens RB. Microglia amplify inflammatory activation of astrocytes in manganese neurotoxicity. J Neuroinflammation. 2017:14:99.

10. Dresselhaus EC, Meffert MK. Cellular Specificity of NF-kappaB Function in the Nervous System. Front Immunol. 2019:10:1043.

11. Kreutzberg GW. Microglia: a sensor for pathological events in the CNS Trends Neurosci. 1996:19:312-8.

12. Subhramanyam CS, Wang C, Hu Q, Dheen ST. Microglia-mediated neuroinflammation in neurodegenerative diseases. Semin Cell Dev Biol. 2019; 94:112-20.

13. Abe H, Ohishi T, Nakane F, Shiraki A, Tanaka T, Yoshida T, Shibutani M Exposure to $\mathrm{MnCl} 2.4 \mathrm{H} 2 \mathrm{O}$ during development induces activation of microglial and perivascular macrophage populations in the hippocampal dentate gyrus of rats. J Appl Toxicol. 2015;35:529-35.

14. Park E, Chun HS. Melatonin attenuates manganese and lipopolysaccharideinduced inflammatory activation of BV2 microglia. Neurochem Res. 2017:42: 656-66. 
15. Afonina IS, Zhong Z, Karin M, Beyaert R. Limiting inflammation-the negative regulation of NF-KB and the NLRP3 inflammasome. Nature Immunology. 2017;18:861-9.

16. Barry R, John SW, Liccardi G, Tenev T, Jaco I, Chen CH, Choi J, Kasperkiewicz $P$, Fernandes-Alnemri T, Alnemri $E$, et al. SUMO-mediated regulation of NLRP3 modulates inflammasome activity. Nat Commun. 2018;9:3001.

17. Walsh JG, Muruve DA, Power C. Inflammasomes in the CNS. Nat Rev Neurosci. 2014;15:84-97.

18. Gong T, Yang Y, Jin T, Jiang W, Zhou R. Orchestration of NLRP3 Inflammasome Activation by lon Fluxes. Trends Immunol. 2018;39:393-406.

19. Kuang S, Zheng J, Yang H, Li S, Duan S, Shen Y, Ji C, Gan J, Xu XW, Li J. Structure insight of GSDMD reveals the basis of GSDMD autoinhibition in cell pyroptosis. Proc Natl Acad Sci U S A. 2017;114:10642-7.

20. Dubois H, Sorgeloos F, Sarvestani ST, Martens L, Saeys Y, Mackenzie JM, Lamkanfi M, van Loo G, Goodfellow I, Wullaert A. Nlrp3 inflammasome activation and Gasdermin D-driven pyroptosis are immunopathogenic upon gastrointestinal norovirus infection. PLoS Pathog. 2019;15:e1007709.

21. Chen H, Lu Y, Cao Z, Ma Q, Pi H, Fang Y, Yu Z, Hu H, Zhou Z. Cadmium induces NLRP3 inflammasome-dependent pyroptosis in vascular endothelial cells. Toxicol Lett. 2016;246:7-16.

22. Pei P, Yao X, Jiang L, Qiu T, Wang N, Yang L, Gao N, Wang Z, Yang G, Liu X, et al. Inorganic arsenic induces pyroptosis and pancreatic beta cells dysfunction through stimulating the IRE1alpha/TNF-alpha pathway and protective effect of taurine. Food Chem Toxicol. 2019;125:392-402.

23. Liao J, Yang F, Tang Z, Yu W, Han Q, Hu L, Li Y, Guo J, Pan J, Ma F, et al. Inhibition of Caspase-1-dependent pyroptosis attenuates copper-induced apoptosis in chicken hepatocytes. Ecotoxicol Environ Saf. 2019;174:110-9.

24. Sarkar S, Malovic E, Harischandra DS, Ngwa HA, Ghosh A, Hogan C, Rokad D, Zenitsky $\mathrm{G}$, Jin $\mathrm{H}$, Anantharam $\mathrm{V}$, et al. Manganese exposure induces neuroinflammation by impairing mitochondrial dynamics in astrocytes. Neurotoxicology. 2018;64:204-18

25. Li SJ, Qin WX, Peng DJ, Yuan ZX, He SN, Luo YN, Aschner M, Jiang YM, Liang DY, Xie BY, Xu F. Sodium P-aminosalicylic acid inhibits sub-chronic manganese-induced neuroinflammation in rats by modulating MAPK and COX-2. Neurotoxicology. 2018;64:219-29.

26. Nkpaa KW, Adedara IA, Amadi BA, Wegwu MO, Farombi EO. Ethanol via Regulation of NF-kappaB/p53 Signaling Pathway Increases ManganeseInduced Inflammation and Apoptosis in Hypothalamus of Rats. Biol Trace Elem Res. 2019;190:101-8.

27. Sarkar S, Rokad D, Malovic E, Luo J, Harischandra DS, Jin H, Anantharam V, Huang X, Lewis M, Kanthasamy A, Kanthasamy AG. Manganese activates NLRP3 inflammasome signaling and propagates exosomal release of ASC in microglial cells. Sci Signal. 2019;12:eaat9900

28. Wang D, Zhang J, Jiang W, Cao Z, Zhao F, Cai T, Aschner M, Luo W. The role of NLRP3-CASP1 in inflammasome-mediated neuroinflammation and autophagy dysfunction in manganese-induced, hippocampal-dependent impairment of learning and memory ability. Autophagy. 2017:13:914-27.

29. Zhang P, Lokuta KM, Turner DE, Liu B. Synergistic dopaminergic neurotoxicity of manganese and lipopolysaccharide: differential involvement of microglia and astroglia. J Neurochem. 2010;112:434-43.

30. Wu X, Zhang H, Qi W, Zhang Y, Li J, Li Z, Lin Y, Bai X, Liu X, Chen X, et al. Nicotine promotes atherosclerosis via ROS-NLRP3-mediated endothelial cell pyroptosis. Cell Death Dis. 2018;9:171.

31. Xu M, Wang L, Wang M, Wang H, Zhang H, Chen Y, Wang X, Gong J, Zhang $\mathrm{JJ}$, Adcock IM, et al. Mitochondrial ROS and NLRP3 inflammasome in acute ozone-induced murine model of airway inflammation and bronchial hyperresponsiveness. Free Radic Res. 2019;53:780-90.

32. Peng DJ, Zhang YW, Li ZC, Li SJ, Cai M, Qin WX, Ou SY, Huang XW, Yuan ZX, Jiang YM. Preventive impacts of PAS-Na on the slow growth and activated inflammatory responses in Mn-exposed rats. J Trace Elem Med Biol. 2019:54:134-41.

33. Ky SQ, Deng HS, Xie PY, Hu W. A report of two cases of chronic serious manganese poisoning treated with sodium para-aminosalicylic acid. Br J Ind Med. 1992:49:66-9.

34. Hong L, Xu C, O'Neal S, Bi HC, Huang M, Zheng W, Zeng S. Roles of Pglycoprotein and multidrug resistance protein in transporting paraaminosalicylic acid and its $\mathrm{N}$-acetylated metabolite in mice brain. Acta Pharmacol Sin. 2014:35:1577-85.

35. Li SJ, Li Y, Chen JW, Yuan ZX, Mo YH, Lu GD, Jiang YM, Ou CY, Wang F, Huang XW, et al. Sodium Para-aminosalicylic Acid Protected Primary Cultured Basal Ganglia Neurons of Rat from Manganese-Induced Oxidative
Impairment and Changes of Amino Acid Neurotransmitters. Biol Trace Elem Res. 2016;170:357-65.

36. Wang F, Wang C, Jiang Y, Deng X, Lu J, Ou S. Protective role of sodium para-amino salicylic acid against manganese-induced hippocampal neurons damage. Environ Toxicol Pharmacol. 2014;37:1071-8.

37. Santos AP, Lucas RL, Andrade V, Mateus ML, Milatovic D, Aschner M, Batoreu MC. Protective effects of ebselen (Ebs) and para-aminosalicylic acid (PAS) against manganese (Mn)-induced neurotoxicity. Toxicol Appl Pharmacol. 2012;258:394-402.

38. Li SJ, Meng HY, Deng XF, Fu X, Chen JW, Huang S, Huang YS, Luo HL, Ou SY, Jiang YM. Protective effects of sodium p-aminosalicylic acid on learning and memory via increasing the number of basal forebrain choline acetyltransferase neurons in manganese-exposed rats. Hum Exp Toxicol. 2015;34:240-8.

39. Yang S, Shao S, Huang B, Yang D, Zeng L, Gan Y, Long D, Chen J, Wang J. Tea polyphenols alleviate tri-ortho-cresyl phosphate-induced autophagy of mouse ovarian granulosa cells. Environ Toxicol. 2020;35:478-86.

40. Li S, Xie A, Li H, Zou X, Zhang Q. A self-assembled, ROS-responsive Janusprodrug for targeted therapy of inflammatory bowel disease. J Control Release. 2019;316:66-78

41. Tong Y, Feng A, Hou X, Zhou Q, Hu X. Nanoholes Regulate the Phytotoxicity of Single-Layer Molybdenum Disulfide. Environ Sci Technol. 2019:53:13938-48.

42. Yang Q, Sun H, Wang X, Yu X, Zhang J, Guo B, Hexige S. Metabolic changes during malignant transformation in primary cells of oral lichen planus: Succinate accumulation and tumour suppression. J Cell Mol Med. 2020;24: 1179-88.

43. Zheng YL, Li L, Jia YX, Zhang BZ, Li JC, Zhu YH, Li MQ, He JZ, Zeng TT, Ban XJ, et al. LINC01554-mediated glucose metabolism reprogramming suppresses tumorigenicity in hepatocellular carcinoma via downregulating PKM2 expression and inhibiting Akt/mTOR signaling pathway. Theranostics. 2019;9:796-810.

44. McKenzie BA, Mamik MK, Saito LB, Boghozian R, Monaco MC, Major EO, Lu J-Q, Branton WG, Power C. Caspase-1 inhibition prevents glia inflammasome activation and pyroptosis in models of multiple sclerosis. PNAS license. 2018:115:E6065-74.

45. Jiang M, Yang $X$, Wu H, Huang Y, Dou J, Zhou C, Ma L. An active domain HF-18 derived from hagfish intestinal peptide effectively inhibited drugresistant bacteria in vitro/vivo. Biochem Pharmacol. 2020;172:113746.

46. Qin W, Wu X, Jia Y, Tong X, Guo C, Chen D, Wang Z, Tan N. Suhuang antitussive capsule inhibits NLRP3 inflammasome activation and ameliorates pulmonary dysfunction via suppression of endoplasmic reticulum stress in cough variant asthma. Biomed Pharmacother. 2019;118:109188.

47. Sun X, Dong S, Li X, Yu K, Sun F, Lee RJ, Li Y, Teng L. Delivery of siRNA using folate receptor-targeted $\mathrm{pH}$-sensitive polymeric nanoparticles for rheumatoid arthritis therapy. Nanomedicine. 2019;20:102017.

48. Li ZC, Wang F, Li SJ, Zhao L, Li JY, Deng Y, Zhu XJ, Zhang YW, Peng DJ, Jiang YM. Sodium Para-aminosalicylic Acid Reverses Changes of Glutamate Turnover in Manganese-Exposed Rats. Biol Trace Elem Res. 2020;197:544-54.

49. Zhu T, Fang F, Sun D, Yang S, Zhang X, Yu X, Yang L. Piceatannol Inhibits P. acnes-Induced Keratinocyte Proliferation and Migration by Downregulating Oxidative Stress and the Inflammatory Response. Inflammation. 2020;43: 347-57.

50. Opdenbosch NV, Gorp HV, Verdonckt M, Saavedra PHV, NMD V, Alves AG, Walle LV, Demon D, Matusiak M, Hauwermeiren FV, et al. Caspase-1 engagement and TLR-induced C-FLIP expression suppress ASC/caspase-8dependent apoptosis by inflammasome sensors NLRP1b and NLRC4. Cell Reports. 2017;21:3427-44.

51. Su Y, Ko ME, Cheng H, Zhu R, Xue M, Wang J, Lee JW, Frankiw L, Xu A,

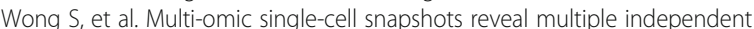
trajectories to drug tolerance in a melanoma cell line. Nat Commun. 2020; 11:2345.

52. Galatro TF, Holtman IR, Lerario AM, Vainchtein ID, Brouwer N, Sola PR, Veras MM, Pereira TF, Leite REP, Möller T, et al. Transcriptomic analysis of purified human cortical microglia reveals age-associated changes. Nat Neurosci. 2017:20:1162-71.

53. Isaksson J, Farooque M, Holtz A, Hillered L, Olsson Y. Expression of ICAM-1 and CD1 1b after experimental spinal cord injury in rats. J Neurotrauma. 1999;16:165-73.

54. Sedgwick JD, Schwender S, Imrich H, Dörries R, Butcher GW, ter Meulen V. Isolation and direct characterization of resident microglial cells from the 
normal and inflamed central nervous system. Proc Natl Acad Sci U S A. 1991;88:7438-42.

55. Lao Y, Dion LA, Gilbert G, Bouchard MF, Rocha G, Wang Y, Lepore N, SaintAmour D. Mapping the basal ganglia alterations in children chronically exposed to manganese. Sci Rep. 2017;7:41804.

56. Tambasco N, Romoli M, Calabresi P. Selective basal ganglia vulnerability to energy deprivation: Experimental and clinical evidences. Prog Neurobiol. 2018;169:55-75.

57. Bjorklund G, Dadar M, Chirumbolo S, Aaseth J. The role of xenobiotics and trace metals in Parkinson's disease. Mol Neurobiol. 2020;57:1405-17.

58. Ueno M, Fujita Y, Tanaka T, Nakamura Y, Kikuta J, Ishii M, Yamashita T. Layer $\checkmark$ cortical neurons require microglial support for survival during postnatal development. Nat Neurosci. 2013;16:543-51.

59. Aloisi F. Immune function of microglia. Glia. 2001;36:165-79.

60. Dempsey C, Rubio Araiz A, Bryson K, Finucane O, Larkin C, Mills EL, Robertson AAB, Cooper MA, O'Neill LAJ, Lynch MA. Inhibiting the NLRP3 inflammasome with MCC950 promotes non-phlogistic clearance of amyloid-beta and cognitive function in APP/PS1 mice. Brain Behav Immun. 2017;61:306-16.

61. Wang S, Yuan YH, Chen NH, Wang HB. The mechanisms of NLRP3 inflammasome/pyroptosis activation and their role in Parkinson's disease. Int Immunopharmacol. 2019;67:458-64.

62. Ahn H, Kim J, Kang SG, Yoon SI, Ko HJ, Kim PH, Hong EJ, An BS, Lee E, Lee GS. Mercury and arsenic attenuate canonical and non-canonical NLRP3 inflammasome activation. Sci Rep. 2018:8:13659.

63. Bae JH, Jang BC, Suh SI, Ha E, Baik HH, Kim SS, Lee MY, Shin DH. Manganese induces inducible nitric oxide synthase (iNOS) expression via activation of both MAP kinase and PI3KJAkt pathways in BV2 microglial cells. Neurosci Lett. 2006;398:151-4.

64. Monzani E, Nicolis S, Dell'Acqua S, Capucciati A, Bacchella C, Zucca FA Mosharov EV, Sulzer D, Zecca L, Casella L. Dopamine, Oxidative Stress and Protein-Quinone Modifications in Parkinson's and Other Neurodegenerative Diseases. Angew Chem Int Ed Engl. 2019;58:6512-27.

65. HaMai D, Campbell A, Bondy SC. Modulation of oxidative events by multivalent manganese complexes in brain tissue. Free Radic Biol Med. 2001:31:763-8.

66. Milatovic D, Zaja-Milatovic S, Gupta RC, Yu Y, Aschner M. Oxidative damage and neurodegeneration in manganese-induced neurotoxicity. Toxicol Appl Pharmacol. 2009;240:219-25.

67. Yang X, Yang H, Wu F, Qi Z, Li J, Xu B, Liu W, Xu Z, Deng Y. Mn inhibits GSH synthesis via downregulation of neuronal EAAC1 and astrocytic $X C T$ to cause oxidative damage in the striatum of mice. Oxid Med Cell Longev. 2018;2018:4235695.

68. Nam E, Han J, Suh JM, Yi Y, Lim MH. Link of impaired metal ion homeostasis to mitochondrial dysfunction in neurons. Curr Opin Chem Biol. 2018;43:8-14.

69. Zsurka G, Kunz WS. Mitochondrial dysfunction and seizures: the neuronal energy crisis. Lancet Neurol. 2015;14:956-66.

70. Tedeschi H. The mitochondrial membrane potential. Biol Rev Camb Philos Soc. 1980;55:171-206

71. Lyamzaev KG, Tokarchuk AV, Panteleeva AA, Mulkidjanian AY, Skulachev VP, Chernyak BV. Induction of autophagy by depolarization of mitochondria. Autophagy. 2018;14:921-4.

72. Jafri MS, Dudycha SJ, O'Rourke B. Cardiac energy metabolism: models of cellular respiration. Annu Rev Biomed Eng. 2001;3:57-81.

73. Lindahl PA, Moore MJ. Labile low-molecular-mass metal complexes in mitochondria: trials and tribulations of a burgeoning field. Biochemistry. 2016:55:4140-53.

74. Zhong Z, Umemura A, Elsa S-L, Liang S, Shalapour S, Wong J, He F, Boassa D, Perkins G, Ali SR, et al. NF-kappab restricts inflammasome activation via elimination of damaged mitochondria. Cell. 2016;164:896-910.

75. Boersma MC, Dresselhaus EC, De Biase LM, Mihalas AB, Bergles DE, Meffert MK. A requirement for nuclear factor-kappaB in developmental and plasticity-associated synaptogenesis. J Neurosci. 2011;31:5414-25.

76. Zhang Y, Reichel JM, Han C, Zuniga-Hertz JP, Cai D. Astrocytic process plasticity and ikkbeta/NF-kappab in central control of blood glucose, blood pressure, and body weight. Cell Metabolism. 2017;25:1091-102 e1094.

77. Jian M, Kwan JS, Bunting M, Ng RC, Chan KH. Adiponectin suppresses amyloid-beta oligomer (AbetaO)-induced inflammatory response of microglia via AdipoR1-AMPK-NF-kappaB signaling pathway. J Neuroinflammation. 2019:16:110.
78. Lee E, Yin Z, Sidoryk-Wegrzynowicz M, Jiang H, Aschner M. 15-DeoxyDelta12,14-prostaglandin J(2) modulates manganese-induced activation of the NF-kappaB, Nrf2, and PI3K pathways in astrocytes. Free Radic Biol Med. 2012:52:1067-74.

79. Ramesh GT, Ghosh D, Gunasekar PG. Activation of early signaling transcription factor, NF-kappaB following low-level manganese exposure. Toxicol Lett. 2002;136:151-8.

80. Zhou G, Meng S, Li Y, Ghebre YT, Cooke JP. Optimal ROS signaling is critical for nuclear reprogramming. Cell Rep. 2016;15:919-25.

81. Louradour I, Sharma A, Morin-Poulard I, Letourneau M, Vincent A, Crozatier M, Vanzo N. Reactive oxygen species-dependent Toll/NF-kappaB activation in the Drosophila hematopoietic niche confers resistance to wasp parasitism. Elife. 2017:6:e25496.

82. Bergsbaken T, Fink SL, Cookson BT. Pyroptosis: host cell death and inflammation. Nat Rev Microbiol. 2009;7:99-109.

83. Sarhan M, Land WG, Tonnus W, Hugo CP, Linkermann A. Origin and Consequences of Necroinflammation. Physiol Rev. 2018:98:727-80.

84. Li SJ, Ou CY, He SN, Huang XW, Luo HL, Meng HY, Lu GD, Jiang YM, Vieira Peres T, Luo YN, Deng XF. Sodium p-aminosalicylic acid reverses subchronic manganese-induced impairments of spatial learning and memory abilities in rats, but fails to restore $\gamma$-Aminobutyric acid levels. Int J Environ Res Public Health. 2017:14:400.

\section{Publisher's Note}

Springer Nature remains neutral with regard to jurisdictional claims in published maps and institutional affiliations.
Ready to submit your research? Choose BMC and benefit from:

- fast, convenient online submission

- thorough peer review by experienced researchers in your field

- rapid publication on acceptance

- support for research data, including large and complex data types

- gold Open Access which fosters wider collaboration and increased citations

- maximum visibility for your research: over $100 \mathrm{M}$ website views per year

At $\mathrm{BMC}$, research is always in progress.

Learn more biomedcentral.com/submissions 